Document downloaded from:

http://hdl.handle.net/10251/61872

This paper must be cited as:

Simancas Coloma, R.; Jorda Moret, JL.; Rey Garcia, F.; Corma Canós, A.; Cantin Sanz, A.; Peral, I.; Popescu, C. (2014). A new microporous zeolitic silicoborate (ITQ-52) with interconnected small and medium pores. Journal of the American Chemical Society. 136(9):3342-3345. doi:10.1021/ja411915c

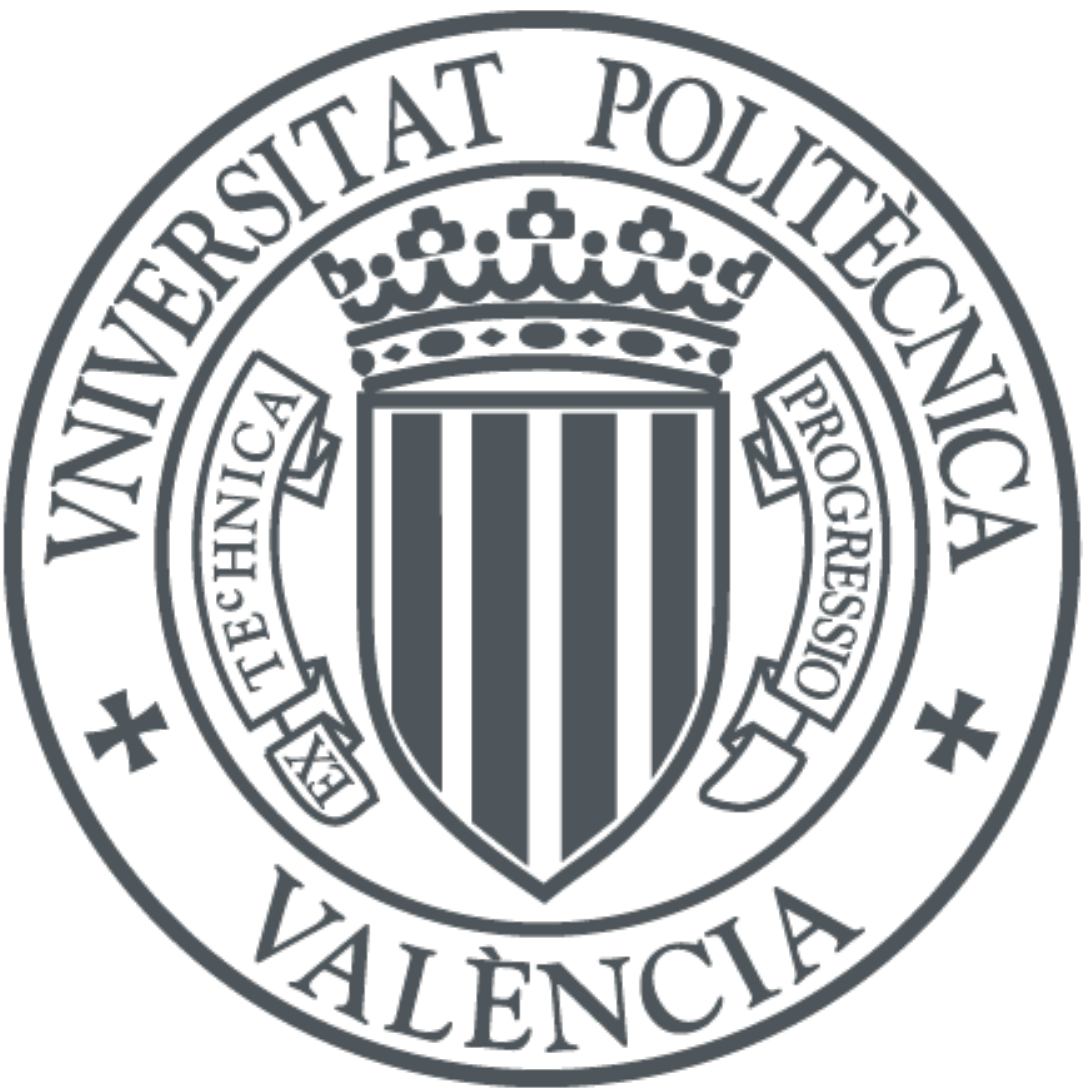

The final publication is available at

http://dx.doi.org/10.1021/ja411915c

Copyright American Chemical Society

Additional Information 


\title{
A new microporous zeolitic silicoborate (ITQ-52) with inter- connected small and medium pores
}

\author{
Raquel Simancas ${ }^{1}$, Jose L. Jordá1, Fernando Rey ${ }^{1, *}$, Avelino Corma ${ }^{1, *}$, Angel Cantín Inma Peral $^{2}$, \\ Catalin Popescu ${ }^{2}$
}

${ }^{1}$ Instituto de Tecnología Química (UPV-CSIC), Universidad Politécnica de Valencia - Consejo Superior de Investigaciones Científicas, Av. de los Naranjos s/n, 46022 Valencia, Spain

${ }^{2}$ ALBA Light Source, Cerdanyola del Vallés, Barcelona, Spain

Supporting Information Placeholder

\begin{abstract}
A new zeolite (named as ITQ-52) having large cavities and small and medium channels has been synthesized. This was achieved by using a new family of aminophosphonium cations as organic structure directing agent (OSDA). These cations contain $\mathrm{P}-\mathrm{C}$ and $\mathrm{P}-\mathrm{N}$ bonds, and therefore they lie between previously reported $\mathrm{P}$-containing OSDA, such as tetraalkylphosphonium and phosphazenes. In this study, it has been found that 1,4-butane-diylbis[tris(dimethylamino)]phosphonium dication is a very efficient OSDA for crystallization of several zeolites, and in some particular conditions, the new zeolite ITQ-52 was synthesized as a pure phase. The structure of ITQ-52 has been solved using high resolution synchrotron X-Ray powder diffraction data of the calcined solid. This new zeolite crystallizes in the space group $I 2 / \mathrm{m}$, with cell parameters $a=$ $17.511 \AA$, $b=17.907 \AA$, $c=12.367 \AA$ and $\beta=90.22$ ‥ The topology of ITQ-52 can be described as a replication of a Composite Building Unit with ring notation $\left[4^{3} 5^{4} 6^{1}\right]$ that gives rise to the formation of an interconnected $8 \mathrm{R}$ and $10 \mathrm{R}$-channel system.
\end{abstract}

Typically, zeolites can be described as crystalline silicabased microporous solids that can carry out a myriad of different processes when doped with the appropriated active sites, such as Al, B, Ga, Ge, Ti, Sn, etc. The catalytic performance of the final porous solids depends mainly on the nature of the heteroatom as well as on their structural pore topologies. Zeolites have been applied for gas adsorption, separation, catalysis, encapsulation or controlled release of molecules, among others, some of them are of industrial application. ${ }^{1-9}$ There is no doubt that this is the driving force for synthesizing new zeolite structures.

Most of the zeolites described in the literature have been obtained by employing tetraalkylammonium cations as organic structure directing agents (OSDAs)..$^{10-13}$ Recently, we have reported a number of new zeolites synthesized by using tetraalkylphosphonium cations (ITQ-26, ${ }^{14}$ ITQ-27, ${ }^{15}$ ITQ-34 ${ }^{16}$ and ITQ-49 $9^{17}$ ) or phosphazenes (ITQ- $47^{18}$ ) as OSDAs. The success of using phosphorous-containing cations as OSDA for zeolite crystallization has moved us to look for different alternatives of organophosphorous cations that are easy and safe to prepare. Then, we found in literature that Wittig-like cations can be quantitatively prepared from the commercially available aminophosphines resulting in phosphorous containing cations.19-22 These new organocations are related to phosphazenes and tetraalkylphosphonium, since they contain $\mathrm{P}-\mathrm{N}$ and $\mathrm{P}-\mathrm{C}$ bonds (see fig. S1 in Supporting Information). On those bases, we have developed a new family of amino-phosphonium cations that introduce interesting features from the point of view of OSDAs for zeolite synthesis. Then, the amino-phosphonium cationic compounds have been used for zeolite synthesis, and here we describe the synthesis and crystal structure of a new zeolite, named as ITQ-52, that was obtained by using 1,4-butane-diylbis[tris(dimethylamino)]phosphonium dication as OSDA (see fig $S_{1}$ in Supporting Information). The structure of ITQ52 has been solved using high resolution synchrotron X-ray powder diffraction data. The material can be described as a medium and small pore zeolite that contains large cavities accessible through 10- and 8-ring windows.

The organophosphorous dication described in this work was obtained by reacting 1,4-di-iodo-butane with tris(dimethylamino)phosphine (see Supporting Information). This OSDA was very stable and was an excellent OSDA for the crystallization of a number of zeolites, including zeolite STF, other unidentified solids and the present ITQ-52, depending on the synthesis gel compositions and temperatures of crystallization. The synthesis conditions and the corresponding observed zeolite phases are shown as Supporting Information (Table $\mathrm{S} 1$ ). In some of the syntheses, a new zeolite, ITQ-52, was identified and after synthesis optimization, it was found that ITQ-52 was obtained as a pure phase upon crystallization at $423 \mathrm{~K}$ for 14 days using the following gel composition:

$$
0.944 \mathrm{SiO}_{2}: 0.028 \mathrm{~B}_{2} \mathrm{O}_{3}: 0.2 \text { OSDA : } 10 \mathrm{H}_{2} \mathrm{O}
$$

The chemical analysis of the zeolite indicates that the $\mathrm{Si} / \mathrm{B}$ ratio in the solid (17.2) was very similar to that employed in the synthesis gel (17), while the $\mathrm{P} /(\mathrm{B}+\mathrm{Si})$ ratio was 0.06 . The $\mathrm{C}, \mathrm{N}$ and $\mathrm{P}$ contents indicate that the organic phosphoruscontaining OSDA remains intact during zeolite formation (see table $S_{2}$ in Supporting Information). This was further 
proved by ${ }^{13} \mathrm{C}$ CP MAS-NMR and ${ }^{31} \mathrm{P}$ MAS-NMR spectroscopies (see Supporting Information). The results clearly prove that the Wittig-like ylide cations are suitable OSDAs for obtaining new zeolites.

The as-made zeolite ITQ-52 was stable upon OSDAs removal either by air calcination or thermal treatment under diluted $\mathrm{H}_{2}$. The highest microporosity was obtained under diluted $\mathrm{H}_{2}$ flow as described in the Supporting Information $\left(439 \mathrm{~m}^{2} / \mathrm{g}\right.$ and $0.196 \mathrm{~cm}^{3} / \mathrm{g}$ BET surface area and $t$-plot micropore volume, respectively). The presence of occluded phosphate-like species inside of the pores of the zeolite ITQ52 was confirmed by chemical analysis and ${ }^{31} \mathrm{P}$ MAS-NMR spectroscopy of the calcined and $\mathrm{H}_{2}$ treated samples (see Supporting Information). Also, "B MAS-NMR spectroscopy indicates that $\mathrm{B}$ atoms are sited at framework positions in the as-made material, and most of the boron remains in framework sites upon thermal decomposition of the occluded OSDA (see Supporting Information).

The X-ray pattern of the calcined sample was obtained in a PANalytical X'Pert PRO diffractometer with BraggBrentano geometry, using $\mathrm{CuK} \alpha$ radiation, as described in the Supporting Information. The sample was calcined in-situ at $873 \mathrm{~K}$ for 5 hours in an Anton Parr XRK-9oo reaction chamber attached to the diffractometer under a continuous flow of dry air to decompose the occluded OSDA and ensure the complete dryness of the sample.

The laboratory XRPD pattern was tentatively indexed using the program TREOR, ${ }^{23}$ suggesting an orthorhombic unit cell with $a=17.937 \AA, b=17.516 \AA$ and $c=12.375 \AA$. Analysis of the systematic extinctions suggested as possible extinction symbol I-(ac)-, corresponding to the space groups Imaz (46), I2cm (46), Imam (74) or Imcm (74). Integrated intensities were extracted by a LeBail analysis of the diffraction pattern using the program FULLPROF, ${ }^{24}$ and the crystal structure was tried to be solved using the program FOCUS, ${ }^{25}$ assuming a pure silica composition. However, none of the proposed groups gave rise to a reasonable structure.

Then, synchrotron X-Ray diffraction experiments were conducted at beamline MSPD of the Spanish Synchrotron Light Source ALBA using a high resolution setup, ${ }^{26-27}$ as described in the Supporting Information. The better resolution allowed a more accurate indexing, and it was found that the true unit cell was monoclinic, slightly distorted with respect to the previous one, with $a=17.511 \AA, b=17.907 \AA$, $c=12.367$ $\AA$ and $\beta=90.22^{\circ}$. Systematic extinctions suggested as extinction symbol $I_{1-1}$, corresponding to the space groups $I_{121}(5)$, $I_{1} m_{1}(8)$ and $I_{12} / m_{1}(12)$. Integrated intensities were extracted again for this new cell, and the crystal structure was solved using FOCUS. Only the space group $I 12 / \mathrm{m} 1$ gave a satisfactory framework, consisting of ten independent $\mathrm{Si}$ positions. Then, the positions of 19 bridging $\mathrm{O}$ atoms were calculated using the program KRIBER, ${ }^{28}$ and the coordinates of all the atoms were optimized geometrically using the program DLS76. ${ }^{29}$ Finally, the structure was fully confirmed by a Rietveld refinement using FULLPROF. However, some small discrepancies in the intensities of the three first peaks were observed due to a partial hydration of the sample. So, the refinement was repeated using the previous in-situ calcined XRPD pattern of the completely dehydrated sample. The refined and experimental patterns are shown in Figure 1. Residuals of the refinement were $R_{w p}=0.096, R_{\exp }=0.038$, $\mathrm{R}_{\mathrm{B}}=0.050$ and $\mathrm{R}_{\mathrm{F}}=0.070$. This structure accomplishes the LID criteria for structural feasibility (see Supporting Information). $3^{\circ}$

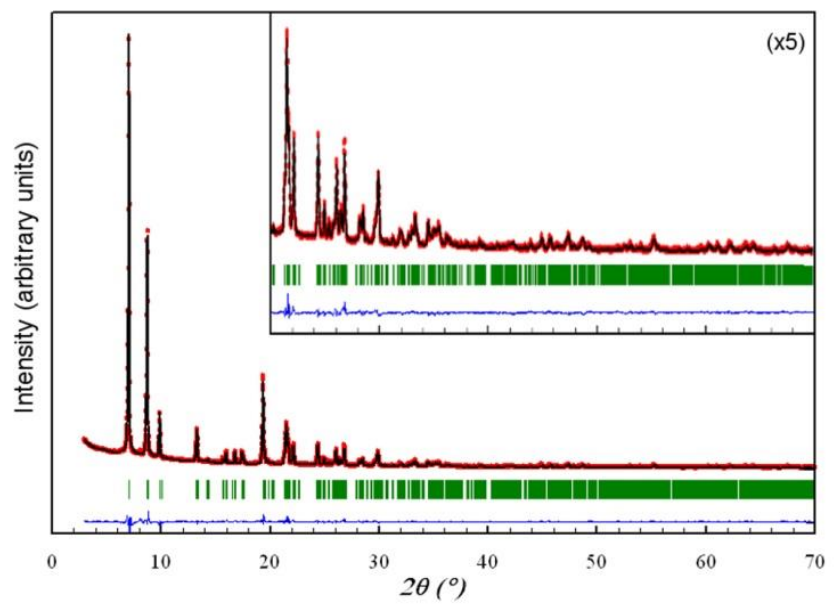

Figure 1. Rietveld refinement of the $\mathrm{x}$-ray diffraction pattern of fully dehydrated ITQ-52 upon calcination at $873 \mathrm{~K}$ (data collected at $303 \mathrm{~K}$ ). Data points show the observed XRPD pattern; the line along these points is the calculated pattern, with the difference profile at the bottom. The vertical tick marks below the pattern give the positions of the Bragg reflections. The inset highlights the agreement in the region from 15 to $75^{\circ}(2 \theta)$.

The structure of ITQ-52 can be constructed using three Composite Building Units (CBUs).31,32 The first CBU, with 16 $\mathrm{T}$-atoms, is the rte (with a ring notation $\left[4^{4} 5^{4} 6^{2}\right]$ ), already observed in zeolites RUB-3 and RUB-10. The second unit, with a ring notation $\left[4^{2} 5^{4} 6^{1}\right]$, contains 13 T-atoms, and it was only observed before in zeolite SSZ-23 (IZA code STT).33 Finally, the last one consists of 58T-atoms forming a large cavity $\left(\left[4^{8} 5^{8} 6^{8} 8^{4} 10^{2}\right]\right)$, accessible through two $10 \mathrm{R}$ and four $8 \mathrm{R}$ apertures (Figure 2). Each large cage in ITQ-52 is connected to six neighbor similar cavities, either through one 8- or one 10-ring window, sharing the corresponding $\mathrm{T}$-atoms. These pore openings correspond to $3.1 \AA$ x $5.8 \AA$ and $5.3 \AA$ x $5.8 \AA$, respectively.

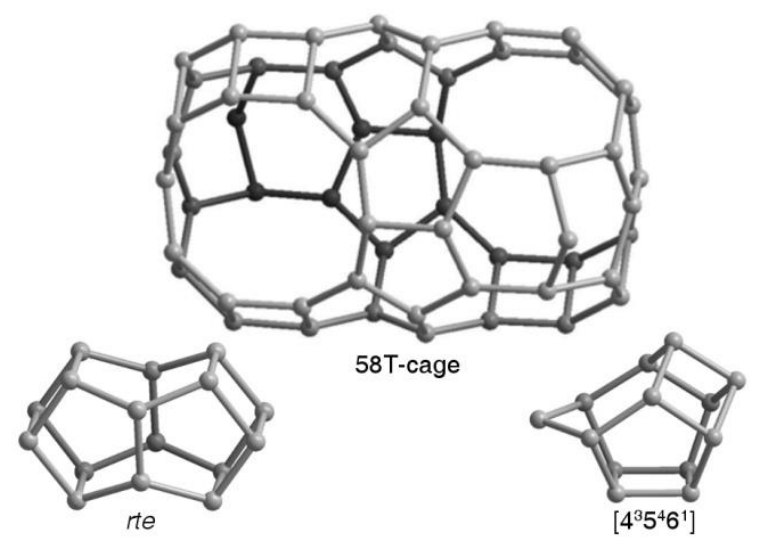

Figure 2. Structure of the CBUs present in ITQ-52: $58 \mathrm{~T}-$ cage, rte and $\left[4^{2} 5^{4} 6^{1}\right]$ unit. Oxygen atoms are omitted for clarity. 


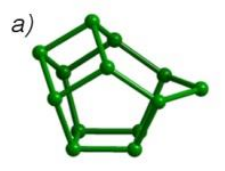

b)

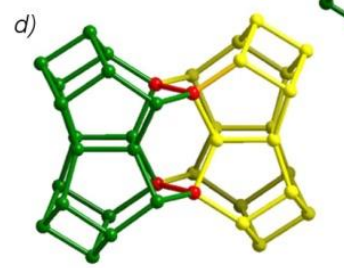

e)
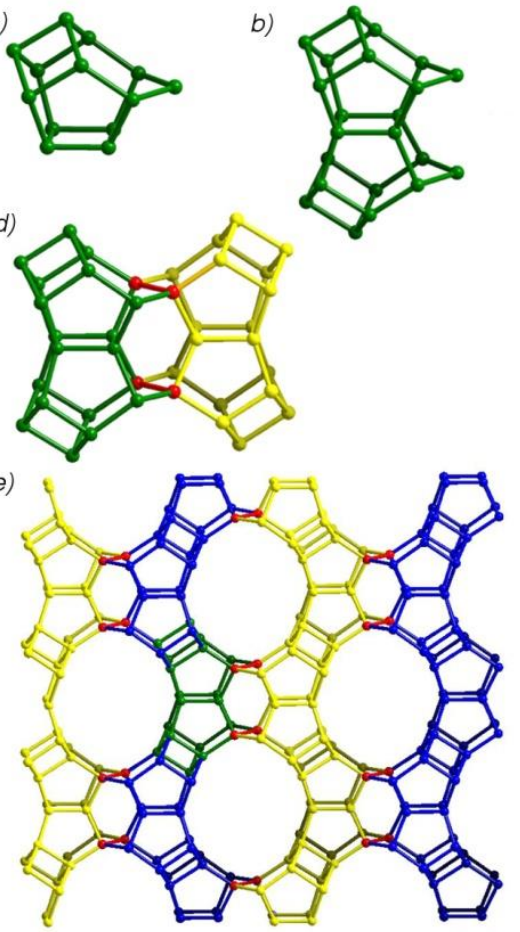

g)

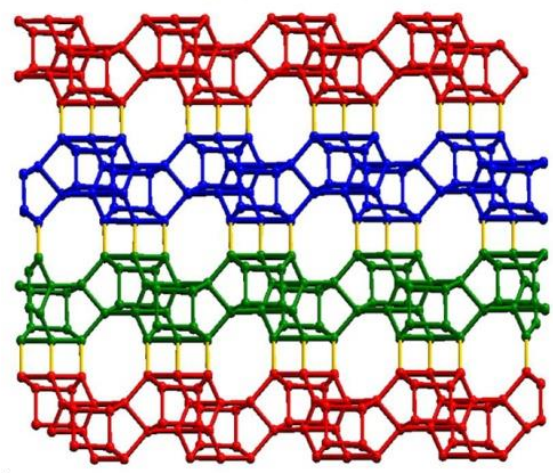

h)

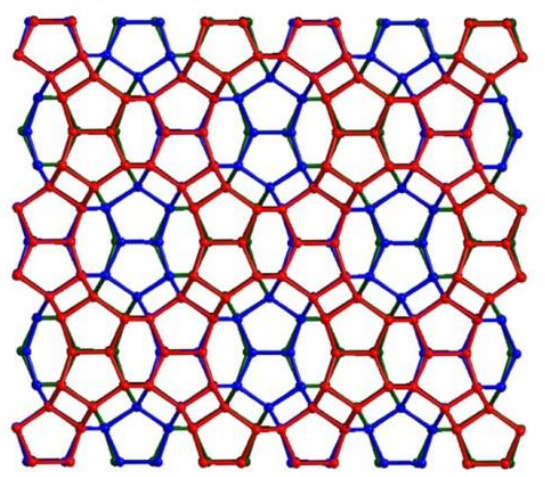

Figure 3. Connection of the $\left[4^{2} 5^{4} 6^{1}\right]$ units to form the ITQ52 structure. a) $\left[4^{2} 5^{4} 6^{1}\right]$ unit; b) dimeric block. c) Connection of the dimers sharing $4 \mathrm{R}$ to form the chain structure; d) chain linkage by sharing one edge of the $6 \mathrm{R}$ (shared T-atoms shown in red). e) Basic layer of ITQ-52. f) Linkage of two dimeric blocks forming a rte unit (bonds due to the additional $\mathrm{O}$ atoms in blue). g) Layer stacking, viewed along [o10], showing the $A B C A B C$... sequence; $h$ ) layer stacking, viewed along [102], (A, B and C layers shown in red, blue or green, respectively). ( $\mathrm{O}$ atoms have been omitted for clarity).

The structure of ITQ-52 can be described from the [ $\left.4^{2} 5^{4} 6^{1}\right]$ unit (Figure 3a). Along all the structure this unit appears always connected to a neighbor unit sharing a $4 \mathrm{R}$, forming a dimeric unit (Figure $3 \mathrm{~b}$ ).

Each dimeric unit is connected to two neighbors by sharing one ${ }_{4} \mathrm{R}$ with each one, forming zigzag chains (Figure $3 \mathrm{c}$ ). These chains can connect to the two closest chains by sharing one edge of each $6 \mathrm{R}$ of the $\left[4^{2} 5^{4} 6^{1}\right]$ units (Figure $3 \mathrm{~d}$ ), forming a layer structure (Figure $3 \mathrm{e}$ ) that containing ${ }_{14} \mathrm{R}$ openings, which corresponds to the middle of the 58T-cages.

Subsequently, these layers are connected to the adjacent ones by incorporating six additional $\mathrm{O}$ atoms to form rte units (Figure $3 \mathrm{f}$ ) between pairs of dimers. In this stacking the ${ }_{14} \mathrm{R}$ are not aligned (Figure $3 \mathrm{~g}$ ), as it follows a ABCABC... stacking order (Figures $3 \mathrm{~h}$ ), giving raise to the formation of large cavities, with 8R and 1oR windows (Figure 4).

The structure of zeolite ITQ-52 is fully consistent with the averaged micropore aperture calculated from the high resolution Ar adsorption isotherm at $87 \mathrm{~K}$ that is $6.1 \AA$, which is slightly larger than that obtained from crystallographic data. However, this discrepancy can be explained considering the presence of large cavities connected through windows, resulting in overestimated pore aperture values as already observed for other well-known zeolites. 34
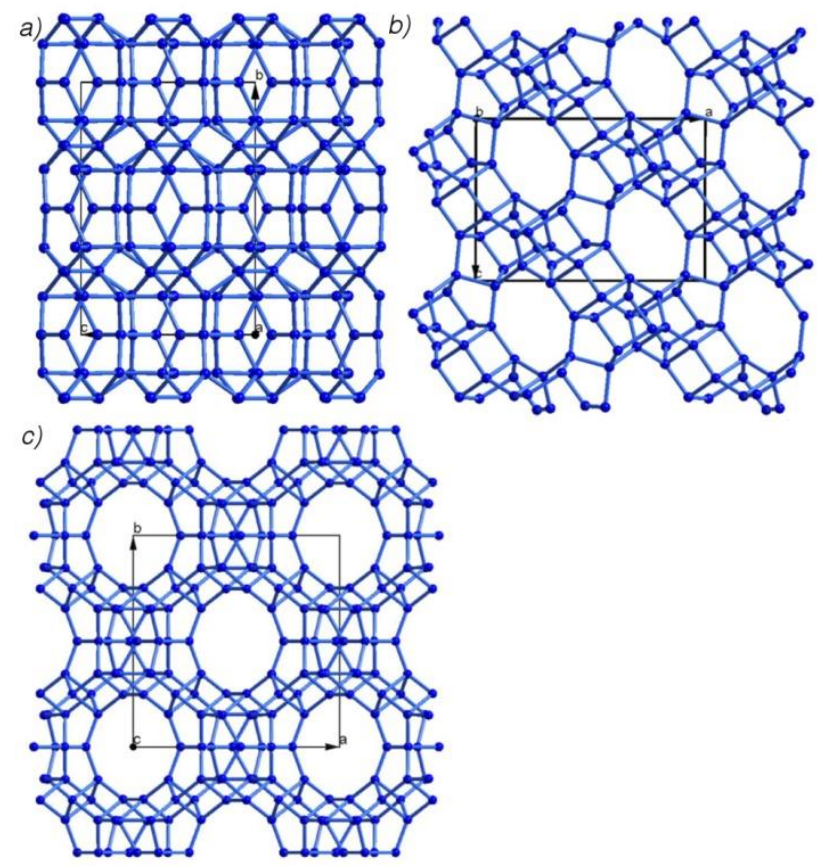

Figure 4. Structure of the zeolite ITQ-52. View along the main crystallographic axis a) [100], b) [010] and c) [0o1].

Then, we can conclude that amino-phosphonium cations can be employed for the sysnthesis of microporous zeolites, being demonstrated by the synthesis of zeolite ITQ-52. The large structural variety and relatively easy preparation of these cations opens a new field of research for creating new zeolitic materials.

\section{ASSOCIATED CONTENT}

\section{Supporting Information}


Synthesis conditions of the OSDA and the zeolite, characterization by chemical analysis, thermal and textural analysis, solid state MAS-NMR, $\mathrm{x}$-ray diffraction, atomic coordinates of ITQ-52, table of interatomic distances and angles, and an $\mathrm{X}$-ray crystallographic (CIF) file of atomic coordinates. This material is available free of charge via the Internet at http://pubs.acs.org.

\section{AUTHOR INFORMATION}

\section{Corresponding Authors}

acorma@itq.upv.es; frey@itq.upv.es

\section{Author Contributions}

The manuscript was written through contributions of all authors.

\section{Notes}

The authors declare no competing financial interests.

\section{ACKNOWLEDGMENT}

Authors thank financial support by the Spanish Government (MAT2012-38567-Co2-01, Consolider Ingenio 2010-Multicat CSD-2009-00050 and Severo Ochoa SEV-2012-0267). R.S. acknowledges to UPV for a FPI predoctoral fellowship. Authors thank ALBA Light Source for beam allocation at beamline MSPD. Authors thank G. Sastre and J. A. Vidal for computational calculations and MAS-NMR experiments, respectively.

\section{REFERENCES}

(1) Wang, Z.; Yu, J.; Xu, R. Chem. Soc. Rev. 2012, 41, 1729.

(2) Zones, S. I. Microporous Mesoporous Mater. 2011, 144, 1.

(3) Shayib, R. M.; George, N. C.; Seshadri, R.; Burton, A. W.; Zones, S. I.; Chmelka, B. F. J. Am. Chem. Soc. 2011, 133, 18728.

(4) Jiang, J.; Yu, J.; Corma, A. Angew. Chem. Int. Ed. 2010, 49, 3120. (5) Bellussi, G.; Carati, A.; Millini, R. In Zeolites and Catalysis: Synthesis, Reactions and Applications; Cejka, J., Corma, A., Zones, S. I., Eds.; Wiley-VCH: Weinheim, Germany, 2o10; Vol. 2, p 449.

(6) Sun, J.; Bonneau, C.; Cantin, A.; Corma, A.; Diaz-Cabañas, M. J.; Moliner, M.; Zhang, D.; Li, M.; Zou, X. Nature 2oo9, 458, 1154.

(7) Corma, A.; Davis, M. E. ChemPhysChem 2oo4, 5, 304.

(8) Corma, A. J. Catal. 2003, 216, 298.

(9) Davis, M. E. Nature 20o2, 417, 813.

(10) Moliner, M.; Willhammar, T.; Wan, W.; González, J.; Rey, F.; Jorda, J. L.; Zou, X.; Corma, A. J. Am. Chem. Soc. 2012, 134, 6473.

(11) Archer, R. H.; Zones, S. I.; Davis, M. E. Microporous Mesoporous Mater. 2010, 130, 255.

(12) Jackowski, A.; Zones, S. I.; Hwang, S.-J.; Burton, A. W. J. Am. Chem. Soc. 2009, 131, 1092.

(13) Burkett, S. L.; Davis, M. E. J. Phys. Chem. 1994, 98, 4647.

(14) Dorset, D. L.; Strohmaier, K. G.; Kliewer, E. C.; Corma, A.; DiazCabanas, M. J.; Rey, F.; Gilmore, C. J. Chem. Mater. 2008, 20, 5325.

(15) Dorset, D. L.; Kennedy, G. J.; Strohmaier, K. G.; Diaz-Cabanas, M. J.; Rey, F.; Corma, A. J. Am. Chem. Soc. 2006, 128, 8862.

(16) Corma, A.; Diaz-Cabanas, M. J.; Jorda, J. L.; Rey, F.; Sastre, G.; Strohmaier, K. G. J. Am. Chem. Soc. 2oo8, 130 (49), 16482.

(17) Hernández-Rodríguez, M.; Jordá, J. L.; Rey, F.; Corma, A. J. Am. Chem. Soc. 2012, 134, 13232.

(18) Simancas, R.; Dari, D.; Velamazán, N.; Navarro, M. T.; Cantín, A.; Jordá, J. L.; Sastre, G.; Corma, A.; Rey, F. Science 2010, 330, 1219.

(19) Kolodiazhnyi, O. I. In Phosphorus Ylides; Wiley-VCH Verlag GmbH; 2007, p 272.

(20) Oleg, I. K.; Valerii, P. K. Russ. Chem. Rev. 1983, 52, 1096.

(21) Trippett, S. Q. Rev. Chem. Soc. 1963, 17, 406.
(22) Odinets, I. L. In Organophosphorus Chemistry: Volume 39; The Royal Society of Chemistry; 2010, p 94.

(23) Werner, P. E.; Eriksson, L.; Westdahl, M. J. Appl. Crystallogr. $1985,18,367$.

(24) Rodriguez-Carvajal, J. Commission on Powder Diffraction (IUCr) Newsletter 2001, 26, 12.

(25) Grosse-Kuntstleve, R. W.; McCusker, L. B.; Baerlocher, Ch. J. Appl. Crystallogr. 1999, 32, 536.

(26) Fauth, F.; Peral, I.; Popescu, C.; Knapp, M. Powder Diffraction (to be published).

(27) Peral, I.; McKinlay, J.; Knapp, M.; Ferrer, S. J. Synchrotron Rad. 2011, 18,1 .

(28) Bialek, R. KRIBER. Crystallographic computation program; ETH Zurich Institut fur Kristallographie: Zurich, Switzerland, 1991.

(29) Baerlocher, Ch.; Hepp, A.; Meier, W. M. DLS-76. Distance least squares refinement program, ETH Zurich Institut fur Kristallographie: Zurich, Switzerland, 1977.

(30) Li, Y.; Yu, J.; Xu, R. Angew. Chem. Int. Ed. 2013, 52, 1673.

(31) McCusker, L. B.; Liebau, F.; Engelhardt, G. Pure Appl. Chem. 2001, 73,381 .

(32) Baerlocher, C.; McCusker, L. B. Database of Zeolite Structures: http://www.iza-structure.org/databases/ (Accessed Nov 18, 2013).

(33) Camblor, M. A.; Diaz-Cabanas, M. J.; Perez-Pariente, J.; Teat, S. J.; Clegg, W.; Shannon, I. J.; Lightfoot, P.; Wright, P. A.; Morris, R. E. Angew. Chem. Int. Ed. 1998, 37, 2122.

(34) Nakai, K.; Sonoda, J.; Yoshida, M.; Hakuman, M.; Naono, H.

Stud. Surf. Sci. Catal. 2007, 170, 831. 
The use of a new family of amino-phosphonium cations as structure directing agents has allowed the synthesis of a new small- and medium-pore zeolite, a silicoborate named ITQ-52. Its structure has been solved using synchrotron $\mathrm{X}$-ray powder diffraction data. This zeolite crystalizes in the space group $I 2 / \mathrm{m}$ with cell parameters $a=17.511 \AA \AA, b=$ $17.907 \AA, c=12.367 \AA$ and $\beta=90.22^{\circ}$, and its pore topology consists in large elongated cavities connected to their neighbors either through small $8 \mathrm{R}$ or medium $10 \mathrm{R}$ openings.

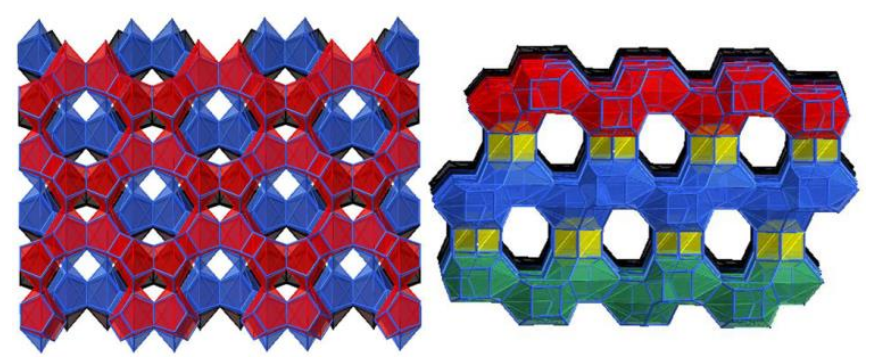

